\title{
A LEUKAEMOID BLOOD PICTURE IN MEGALOBLASTIC ANAEMIA OF THE PUERPERIUM
}

BY

\author{
G. SCLARE AND J. CRAGG
}

From the Department of Pathology, Withington Hospital, West Didsbury, Manchester

(RECEIVED FOR PUBLICATION APRIL 10, 1957)

Blood pictures simulating leukaemia are known to occur in a variety of conditions, of which acute infections and tuberculosis are the chief. The following three cases are added to the small number already recorded in association with megaloblastic anaemia in the puerperium. They were all admitted to the same obstetric unit, and were encountered within a period of just over three months.

\section{Case Reports}

Case 1.-Aged 32. Two previous pregnancies normal. Tiredness, swelling of ankles during last three weeks of third pregnancy. Labour normal, no undue blood loss. Admitted to hospital 10 days after delivery.

Treatment during Pregnancy.-None. During the five days before admission she had taken eight capsules of a compound haematinic, which did not contain vitamin $B_{12}$ but included a minute quantity of folic acid (estimated by the manufacturers as $240 \mu$ g. per capsule).

Clinical Condition.--Exhaustion and extreme pallor on admission. Scanty purpuric spots on the abdominal wall, which faded within 24 hours. Intermittent mild pyrexia for five days. A small breast abscess developed on the thirteenth day; this responded rapidly to incision and treatment with "aureomycin." Liver and spleen were not palpable at any stage.

Initial Blood Findings.-Haemoglobin was 2.9 g. \%. White cells numbered 23,600 per c.mm. The red cells appeared normochromic and normocytic, though a few nucleated red cells, readily identifiable as megaloblasts, were present in the peripheral blood. Over $45 \%$ of the white cells were immature granulocytes, of which many were giant myelocytes and $1.5 \%$ were blasts. The mature polymorphs showed hypersegmentation of their nuclei.

Other Investigations. - The sternal marrow on the first day showed megaloblastic hyperplasia. The myeloid series also appeared unduly active, with numerous mitotic figures. but the proportion of blast cells was not increased. Giant myelocytes and metamyelocytes were prominent. Free hydrochloric acid was present in the gastric juice. The faecal fats were normal.

Treatment.-The patient had been admitted during the night, and transfusion of 2 pints of blood was begun almost immediately. The following afternoon folic acid therapy was instituted, beginning with $30 \mathrm{mg}$. intravenously. For the next three days $15 \mathrm{mg}$. was given intramuscularly twice a day, and oral folic acid, $10 \mathrm{mg}$. three times daily, was continued for a further three months. A course of intravenous iron therapy was given from the fifth to the eleventh days, and oral iron substituted thereafter.

Course.-The total white cell count at first fell rapidly, but on the third day it rose again and remained at 20,000 on the fourth and fifth days, the proportion of immature granulocytes reaching $60 \%$. There was a concomitant increase in the number of circulating nucleated red cells. Subsequently, both the total white cell count and the proportion of immature forms gradually fell to normal, the total count reaching 9,900 on the 19 th day and the immature cells disappearing by the 75 th day. The haemoglobin level, the red cell count, and the packed cell volume all showed a satisfactory response to folic acid therapy. There was a fairly rapid change in the appearance of the red cells in the stained film; the initial normochromic normocytic picture gave way within four days to one of frank macrocytosis, indistinguishable from that of Addisonian anaemia, with a subsequent slow return to normal. The patient was discharged from hospital on the 19th day, and has since attended regularly as an out-patient.

Case 2.-Aged 37. Eight previous pregnancies normal. Admitted to hospital 11 days after premature delivery of ninth child.

Treatment during Pregnancy.-None. Eight tablets of ferrous gluconate before admission.

Clinical Condition.-Marked pallor, with a distinct yellowish tinge on admission. Low-grade pyrexia. No evidence of infection. Liver just palpable ; spleen not palpable. 
Initial Blood Findings.-Haemoglobin was $3.8 \mathrm{~g} . \%$ and red blood cells 1.3 millions per c.mm. The white blood cells numbered 10,000 per c.mm., of which $11 \%$ were immature granulocytes. The red cells varied considerably in size and shape, but only a few were macrocytic. Intermediate and late megaloblasts were seen in the peripheral blood. Giant metamyelocytes and myelocytes were present, as well as hypersegmented polymorphs.

Other Investigations. - The sternal marrow, on the second day, showed megaloblastic hyperplasia; there was also hyperplasia of the myeloid series, but the proportion of blast forms was not excessive.

Free acid was present in the gastric juice. The faecal fats were normal.

Treatment.-One pint of packed cells was transfused on the first day. Folic acid therapy was begun on the third day, according to the same scheme as for Case 1, but omitting the initial intravenous dose. A course of intravenous iron was begun on the fourth day. Oral folic acid and iron were substituted for parenteral therapy, and were continued until the blood picture had returned to normal.

Course.-The total white cells had risen sharply to 24,500 per c.mm. on the fifth day, 52 hours after the first dose of folic acid, with an accompanying rise in the proportion of immature granulocytes to $25^{\circ}$, and in the number of circulating nucleated red cells. The white cell count reached 26,500 on the sixth day, with $27.5 \%$ immature granulocytes, including $1.5 \%$ blasts. The total count returned to normal within a few days, and the nucleated red cells disappeared from the blood shortly afterwards, but the immature granulocytes persisted for a further six weeks. By the time the leukaemoid response had reached its height, the red-cell picture had become frankly macrocytic. The anaemia responded satisfactorily to folic acid and iron therapy.

The patient was discharged on the twentieth day. She has attended regularly as an out-patient, and remains well.

Case 3.-Aged 28. Three previous pregnancies; the latter two had been followed by megaloblastic anaemia, treated with folic acid. Megaloblastic anaemia, verified by marrow biopsy, had recurred 16 months after the last pregnancy, and had again responded to folic acid. Myeloid reactions were not observed on any of these occasions. Admitted two hours after delivery of fourth child; labour had been normal, with little blood loss.

Treatment during Pregnancy.-In view of the previous history, folic acid and iron had been prescribed, but had not been taken, during pregnancy. The diet had been extremely poor. Haemoglobin levels only were estimated during pregnancy : they showed a steady fall from $11.0 \mathrm{~g} . \%$ in the fourth month to $5.5 \mathrm{~g}$. \% six days before delivery. Treatment during the last six days comprised only a single injection of vitamin $B_{12}$ and a single tablet of folic acid.
Clinical Condition.-Deathly pale on admission. No pyrexia. No purpura. Liver palpable, one fingerbreadth ; spleen not palpable. No evidence of infection.

Initial Blood Findings.-Haemoglobin was $3.1 \mathrm{~g} . \%$. and red cells 800,000 per c.mm. The white cells $\triangle$ numbered 7.500 per c.mm., including $1.5 \%$ immature o granulocytes. The stained film showed frank macrocytosis; occasional megaloblasts were seen.

Other Investigations. - Sternal marrow (on day of $\vec{\omega}$ admission): megaloblastic hyperplasia; white cell $\stackrel{\mathscr{S}}{\circ}$ precursors not unduly active. but included giant $\frac{8}{8}$ myelocytes. Hypochlorhydria. Faecal fats normal.

Treatment.-Folic acid therapy was begun 10 hours $\overrightarrow{.}$ after admission. She received $30 \mathrm{mg}$. intravenously twice daily for three days, $15 \mathrm{mg}$. intramuscularly of twice daily for three days, and subsequently took 은 $10 \mathrm{mg}$. by mouth three times daily. A course of intravenous iron lasted from the sixth to the twelfth $c$ day. Because of her poor clinical condition, 1 pint of blood was transfused on the seventh day. Oral folic acid and iron were continued after her discharge from $₹$ hospital on the 17 th day.

Course-On the third day, the total white cell of count had risen to 26,000 per c.mm., with 17 to $21 \%$ of immature granulocytes, and there was a simultaneous outpouring of nucleated red cells. The total white cell count fell to 18,000 on the fourth day, 12.000 on the sixth day, and 8.500 on the seventh day, but the immature cells persisted, in fluctuating proportions. $\stackrel{\mathbb{Q}}{\varrho}$ for a further three weeks. The response of the $\vec{F}$ anaemia to folic acid therapy was satisfactory. Macrocytosis ceased to be evident after two weeks.

\section{Discussion}

These three cases of megaloblastic anaemia, presenting in the puerperium, were all associated with a leukaemoid picture in the peripheral blood. In two cases, the leukaemoid reaction was present initially, and became more pronounced within two days of the start of folic acid therapy. In the third, the reaction was negligible initially, but $\frac{D}{0}$ became evident within two days of starting therapy. In all three cases, the total and differen- $N$ tial white cell counts gradually returned to $N$ normal while the same therapy was continued.

A search of the literature has revealed three cases-two of them fatal-in which a proved megaloblastic anaemia in the puerperium was $\stackrel{0}{工}$ associated with a myeloid response. That reported $\stackrel{\mathcal{D}}{+}$ by Foy, Kondi, and Murray (1946) followed an ? abortion; death occurred several months later, and $\frac{0}{0}$ the case was regarded as one of "leukanaemia," though it is quoted by Whitby and Britton (1953) $\frac{\Omega}{\mathbb{D}}$ among "authentic cases of pernicious anaemia $\varrho$ complicated by myeloid leukaemia." Gillespie and Ramsay (1948) recorded a case which ended 8 
fatally five weeks after delivery; the total white cell count was consistently low, but the differential count included 20 to $50 \%$ of myelocytes, promyelocytes, and myeloblasts.

The case reported by Ritchie (1952) bears the closest resemblance to the present series; a severe megaloblastic anaemia in the puerperium was accompanied by an extensive myeloid response, which decreased rapidly over a period of five days, and completely disappeared within three weeks. As in Case 3, the initial total white cell count was normal, with a very few myelocytes and blasts in the peripheral blood, and the outpouring of immature granulocytes was observed two days after institution of folic acid therapy.

The case described by Scott (1948) of a leukaemia-like reaction in the puerperium, associated with a severe anaemia, may have been a further example. The nature of the anaemia was not established, however, and the leukaemoid response was attributed to a single dose of sulphadiazine.

Disturbances of granulopoiesis are probably not uncommon in megaloblastic anaemia of pregnancy, just as they are a usual feature of the blood picture in Addisonian anaemia. According to Callender (1944), " a few myelocytes " are "always present" in megaloblastic anaemia of pregnancy, and Wintrobe (1956) states that, though leucopenia is more frequent than leucocytosis, a few immature forms are often found, as well as multiple segmented neutrophils. The presence of macrogranulocytes in the marrow is considered by Lowenstein, Pick, and Philpott (1955) to be of diagnostic significance.

Heck (1932) observed leukaemoid reactions in association with Addisonian megaloblastic anaemia. He noted that they occurred primarily in cases in which the red cell count was below $2,000,000$ per c.mm., and that there might be an increase in the amount of immaturity within a short time of the institution of specific therapy.

The circumstances under which leukaemoid reactions may occur have been elaborately classified by Hill and Duncan (1941), and further considered by Hilts and Shaw (1953). In the present cases, it seems unlikely that any factors other than megaloblastic anaemia and the administration of folic acid were related to the myeloid response. The only clinically evident infection was the breast abscess in Case 1, and this developed only when the myeloid response had almost subsided. No antibiotics or other drugs had been taken, apart from the negligible amounts of haematinics already mentioned.
Considering the present cases and Ritchie's together, it is evident that myeloid responses of varying degree may accompany megaloblastic anaemia of the puerperium, and that they may be temporarily accentuated during folic acid therapy. It is possible that, in all four cases, the association between folic acid therapy and accentuation of the myeloid response was fortuitous, but the close similarity of the time relationships in all four cases makes this highly unlikely. It is difficult to resist the conclusion that folic acid is capable of accentuating the abnormal myeloid response, whether it is already clearly evident, as in Cases 1 and 2, or of very slight degree, as in Case 3 and Ritchie's case.

The part played by folic acid may be explicable in the light of its known effects on white cell development. Marinone and Lourau (1948), studying the effect of folic acid on the bone marrow in rabbits, noted that myelocytes and metamyelocytes increased at the expense of myeloblasts and promyelocytes, and concluded that in the normal animal folic acid acts as a maturation factor for the myeloid cells. The discovery by Farber, Diamond, Mercer, Sylvester, and Wolff (1948) of the beneficial, if temporary, effect of folic acid antagonists on acute leukaemia was prompted by the observation that administration of folic acid conjugates to children with acute leukaemia resulted in an "acceleration phenomenon," demonstrable in the marrow and viscera at necropsy. Rapid haematological and clinical relapse followed the trial of folic acid in chronic myeloid leukaemia (Heinle and Welch, 1948), and haematological improvement accompanied the withdrawal of folic acid. Such observations are in keeping with Swendseid, Bethell, and Bird's (1951) finding that in acute leukaemia rapidly proliferating leucocytes have a content of folic acid approximately five times that of the normal leucocyte.

It would appear that the present cases represent something analogous to Farber's "acceleration phenomenon," occurring not in leukaemia but in a transient leukaemoid reaction accompanying megaloblastic anaemia.

Lastly, the absence of macrocytosis in Case 1, when first seen, deserves comment. It is recognized that the megaloblastic anaemia of pregnancy is not necessarily a macrocytic anaemia; it may be normocytic or even microcytic (Lillie, Gatenby, and Moore, 1954 ; Lowenstein et al., 1955). Scott (1954) noted that in such cases after a few injections of intravenous iron the red cells tended to become macrocytic, and typical megalo- 
blasts could be seen in the blood films; she regarded this phenomenon as so constant as to be a useful aid to diagnosis when sternal punctures could not be carried out. Intravenous iron, however, cannot be implicated in Case 1 , as the conversion of a normocytic to a macrocytic picture occurred before the first dose of iron was administered. Unless folic acid played a part in this also, the more probable explanation is that the megaloblastic change in the bone marrow had occurred only a short time previously, and was not clearly reflected in the peripheral blood for several days.

\section{Summary}

Three cases are presented in which megaloblastic anaemia, first diagnosed in the puerperium, was accompanied by a leukaemoid blood picture of myeloid type. All recovered on folic acid and intravenous iron therapy. The probable part played by folic acid in accentuating the myeloid response is discussed.
Our thanks are due to Dr. L. Stent, consultant $\Rightarrow$ pathologist, and Dr. R. W. Burslem and Dr. R. Newton, consultant obstetricians, for permission too publish. and to Mr. W. Lawson for technicalo assistance.

\section{REFERENCES}

Callender, S. T. E. (1944). Quart. J. Mfed., 13, 75.

Farber, S., Diamond, L. K., Mercer, R. D., Sylvester, R. F., Jr., and Wolff, J. A. (1948). New Engl. J. Med., 238, 787.

Foy, H., Kondi, A.. and Murray, J. F. (1946). J. Path. Bact., 58, 157.

Gillespie. M.. and Ramsay, A. M. (1948). Brit. med. J., 1, 828.

Heck, F. J. (1932). Amer. J. clin. Path., 2, 443.

Heinle, R. W., and Welch, A. D. (1948). J. clin. Invest., 27, 539. O Hill, J. M., and Duncan, C. N. (1941). Amer. J. med. Sci., 201, 8470

Hilts, S. V., and Shaw, C. C. (1953). New Engl. J. Med., 249, 434. C

Lillie, E. W., Gatenby, P. B. B., and Moore, H. C. (1954). Irish J. med. Sci., p. 304

Lowenstein, L., Pick, C., and Philpott, N. (1955). Amer. J. Obstet $\overrightarrow{-}$ Ginec.. 70, 1309.

Marinone, G., and Lourau, M. (1948). Sang, 19, 129.

Ritchie, G. M. (1952). J. clin. Path., 5, 329.

Scott, J. M. (1954). J. Obstet. Gynaec. Brit. Emp., 61, 646.

Scott, L. G. (1948). J. med. Soc. N.J., 45, 115. Swendseid, M. E., Bethell, F. H., and Bird, O.D. (1951). Cancer Res. 일
11,864.

Whitby, L. E. H., and Britton, C. J. C. (1953). Disorders of the Blood 7 th ed., p. 545 . Churchill, London.

Wintrobe, M. M. (1956). Clinical Hematology, 4th ed., p. 515. Kimpton, London. 